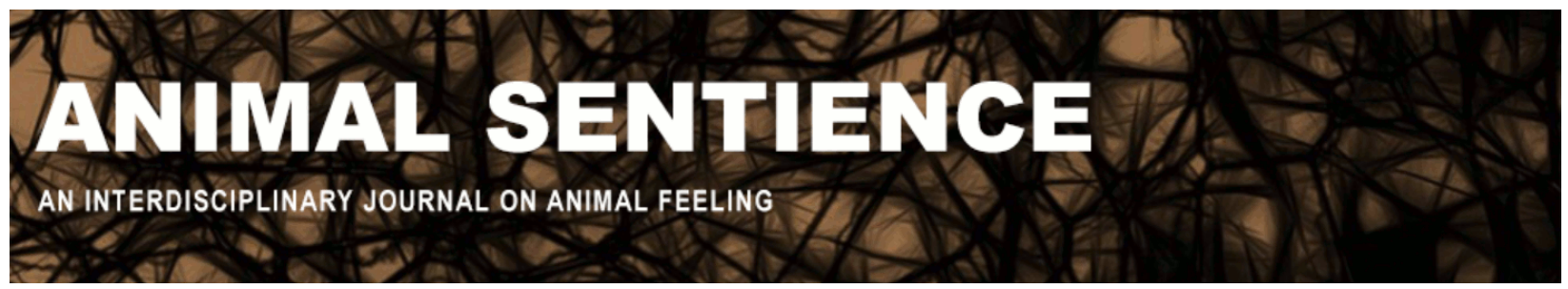

Morsella, Ezequiel and Reyes, Zaviera (2016) The difference between conscious and unconscious brain circuits. Animal Sentience 11(10)

DOI: $10.51291 / 2377-7478.1178$

Date of submission: 2016-11-18

Date of acceptance: 2016-11-21

(c)

This article has appeared in the journal Animal

Sentience, a peer-reviewed journal on animal

cognition and feeling. It has been made open access,

free for all, by WellBeing International and deposited

in the WBI Studies Repository. For more information,

please contact

wbisr-info@wellbeingintl.org.

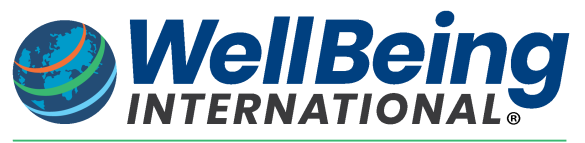

SOLUTIONS FOR PEOPLE, ANIMALS AND ENVIRONMENT 


\title{
The difference between conscious and unconscious brain circuits
}

\author{
Commentary on Reber on Origins of Mind
}

\author{
Ezequiel Morsella ${ }^{1,2}$ \& Zaviera Reyes ${ }^{1}$ \\ ${ }^{1}$ Department of Psychology, San Francisco State University \\ 2 Department of Neurology, University of California, San Francisco
}

\begin{abstract}
Theoretical frameworks in which consciousness is an inherent property of the neuron must account for the contrast between conscious and unconscious processes in the brain and address how neural events can ever be unconscious if consciousness is a property of all neurons. Other approaches have sought answers regarding consciousness by contrasting conscious and unconscious processes and through investigating the complex interactions between the two kinds of processes, as occurs most notably in human voluntary action. In voluntary action, consciousness is associated most, not with motor control or low-level perceptual processing, but with the stage of processing known as action selection.
\end{abstract}

Keywords: animal consciousness, action selection, passive frame theory

Ezequiel Morsella, Director of the Action and Consciousness Laboratory, San Francisco State University (SFSU), does research on the differences between the conscious and unconscious brain circuits underlying human action production.

http://online.sfsu.edu/morsella/people.html

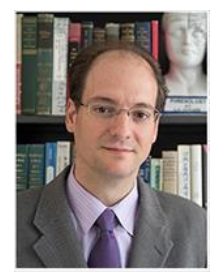

Zaviera Reyes, a graduate of the Master of Arts program at San Francisco State University (SFSU), investigates the behavioral and cognitive mechanisms, including conscious processes, associated with responding adaptively to everyday stressors and with resilient outcomes.

http://online.sfsu.edu/morsella/people.html

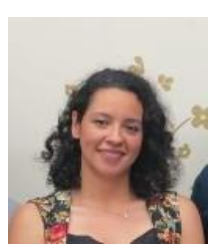

Reber (2016) introduces a thoughtful, counterintuitive approach to the problem of how consciousness emerges from biological events. The approach is progressive in several ways, including that it is descriptive (describing the products of nature as they evolved to be rather than as they should be) and focuses on the most basic and presumably most tractable forms of conscious processing.

When adopting such a descriptive standpoint, it is evident that, in the nervous system, there are neural events that are associated with conscious processing and neural events that are not at all associated with conscious processing. Thus, in every field of study in psychology and in neuroscience, there exists the distinction between conscious and unconscious processes. 
(Passive Frame Theory attempts to explain, as parsimoniously as possible, the difference between conscious and unconscious processes; Morsella, Godwin, Jantz, Krieger, \& Gazzaley, in press.) For example, in perception research, there exists the distinction between supraliminal and subliminal; in memory research, there is the contrast between explicit and implicit processes. Similarly, in research on motor cognition and on language, the conscious aspects of voluntary action or of speech production are contrasted with the unconscious aspects of, for example, motor programming and syntax. Various fields also contrast "controlled" processes (which tend to be conscious) and "automatic" processes (which are often unconscious). In addition, in neuroscience, there is a growing consensus (Morsella et al., in press) that consciousness is associated with only a subset of all the processes and regions of the nervous system. This subset of processes seems to be qualitatively distinct from its unconscious counterparts in physical makeup/organization or functioning. Complex forms of unconscious processes can be found at all stages of processing, including low-level perceptual analysis, semantic-conceptual processing, and motor programming (Morsella \& Bargh, 2011). Dramatic forms of unconscious processing are found in cases in which the entire stimulus-response arc is mediated unconsciously, as in the case of some reflexes and automatisms (e.g., in neurological conditions). Theorists who propose that consciousness is an inherent property of the nerve cell, or of all matter (as in panpsychism), must account for the contrast between conscious and unconscious processes and explain how neural events can ever be unconscious if consciousness is a property of all nerve cells. In short, do such theoretical frameworks allow for the existence of unconscious neural processes?

Faced with this challenge, proponents of such accounts could posit that cells associated with unconscious processes (e.g., peristalsis and the pupillary reflex) are really not unconscious but, instead, have a form of consciousness that is impoverished or otherwise different from normal human consciousness. But now a new problem arises, one that is no less difficult than, and may be one and the same as, the "hard problem" of consciousness. This is because a proponent of the view that consciousness is an inherent property of the nerve cell must then explain why there exists a contrast between this strange, newly-identified form of consciousness (which occupies most of nervous function, including activities in the enteric nervous system) and normal consciousness (e.g., explicit processes and subjectivelyexperienced pain). It could be argued that the latter involves neural circuitry with different properties, perhaps more complex than the former. But it remains mysterious what these properties and the other differences between the two kinds of consciousness are. Addressing this issue would be tantamount to explaining how neural circuits generate conscious processing.

\section{Alternative Approaches to the Study of Consciousness}

To solve the riddle of consciousness and the brain, perhaps the lowest hanging fruit is to explain the contrast between conscious and unconscious processes within adult humans, who, unlike single-celled organisms, can reliably self-report their conscious experiences. At present, in humans there are many contrasts (e.g., the pupillary reflex versus conscious pain) that remain difficult to explain. Current approaches that have granted that unconscious processes do exist have begun to look for answers by contrasting conscious and unconscious processes and by investigating the complex interactions between the two kinds of processes, as occurs most 
notably in human voluntary action. Voluntary action depends on the complex interplay between a medley of conscious and unconscious processes. For example, of all the stages of processing that lead to an overt behavior in response to an external stimulus, it seems that consciousness is associated most with what has been regarded as the "central process" of action selection (Proctor \& Vu, 2010). Consciousness is not as closely associated with motor control, which is mostly unconscious, or with low-level perceptuo-semantic analysis, which is mostly consciouslyimpenetrable (Morsella et al., in press). With a descriptive approach, detecting the contrast between conscious and unconscious processes in the human nervous system is somewhat inevitable (Morsella \& Poehlman, 2013). Positing that consciousness is an inherent property of nerve cells, or of physical matter, does not at this stage of understanding illuminate this enigmatic contrast.

Even if consciousness is a property of the cell, the question remains, What is it about the cell that gives it the properties associated with consciousness? Such a question is far more daunting than what non-experts may surmise: Investigators focusing on consciousness are not only incapable of having an inkling regarding how something like consciousness could arise from something like cells or brain circuitry, they cannot even begin to fathom how something like consciousness could emerge from any set of real or hypothetical circumstances. Reber's thoughtful framework provides a descriptive, falsifiable, and intellectually stimulating perspective on this long-studied mystery: How consciousness emerges from biological events.

\section{References}

Morsella, E., \& Bargh, J. A. (2011). Unconscious action tendencies: Sources of 'un-integrated' action. In J. T. Cacioppo \& J. Decety (Eds.), The Oxford handbook of social neuroscience (pp. 335-347). New York: Oxford University Press.

Morsella, E., \& Poehlman, T. A. (2013). The inevitable contrast: Conscious versus unconscious processes in action control. Frontiers in Psychology, 4, 590. doi: 10.3889/fpsyg.2013.00590.

Morsella, E., Godwin, C. A., Jantz, T. J., Krieger, S. C., \& Gazzaley, A. (in press). Homing in on consciousness in the nervous system: An action-based synthesis. Behavioral and Brain Sciences [Target Article].

Proctor, R. W., \& Vu, K.-P. L. (2010). Action selection. In I. B. Weiner \& E. Craighead (Eds.), The Corsini encyclopedia of psychology, volume 1 (pp. 20-22). Hoboken, NJ: John Wiley.

Reber, A. S. (2016). Caterpillars, consciousness and the origins of mind. Animal Sentience 2016.106. 